\title{
Investigating the Beliefs about Self of College Students in Solving Mathematical Problem
}

\author{
Riny Arviana \\ Universitas Pendidikan Indonesia \\ riny.arviana@upi.edu
}

\begin{abstract}
Human life is about an entity which always experiences the changes. Each sector of our life involving education, technology, economics, and social will be advanced gradually. These advancements let everyone to encounter the new problems or challenges for sure. Knowing this fact, ability in solving a problem is a must for us to have. The process of solving problem is influenced by several factors, like belief which is called belief system in mathematics education. Mathematics education is assumed to be able to grow and enhance one's beliefs system in solving a problem. This research is a case study which concerns a part of beliefs system namely beliefs about self. This study aimed to investigate the beliefs about self of college students who are 18-22 years old in solving mathematical problem. Four voluntary participants were given mathematical problem and interviewed separately. The result shows that each participant has beliefs about self which is positive or negative oriented. One of the factors promoting the beliefs about self is experience. It is recommended to conduct a similar study with larger sample.
\end{abstract}

Keywords: beliefs system, beliefs about self, college student

\section{Introduction}

Life that involves various sectors will always experience the changes gradually. These changes are used to encourage the appearance of the new problems and challenges. People do not ever know what kind of problems that will come to their life. Problems always demand the solution. Solution is obtained through the process of solving problems done by someone. We need to solve the problems independently. Ability in solving problem is not a theoretical skill that can be taught but an empirical skill obtained through experience and training. This is the importance of mathematics education to be learned by everyone. Mathematics education will train each people in solving problems.

Mathematics is a discipline which its main purpose is to shaping the one's point of view or thinking way in solving problem. Based on this point of view, people then turn to think the solution for the problem that they find. Math prepares a person to be able to deal with changing circumstances in the life of the ever-evolving world through practice behavior on the basis of logical, rational, critical, accurate, honest, effective, and efficient (Suherman, 2003). Thus, through a mathematical education a person is not only expected to master mathematical symbols, formulas, and procedures but also apply their mathematical mindset in daily life.

Solving problems is a comprehensive activity that involves a number of abilities, both cognitive and affective abilities (Ozturk \& Guven, 2016). One of the affective abilities needed in solving mathematical problems is beliefs. Belief is the principles of a person who will influence 
him in thinking, making decisions, and behaving. In mathematics education, the term belief is namely as beliefs system.

Beliefs system is a research topic that is quite interesting for many researchers, especially researchers in the field of education. Stylianides \& Stylianides (2014) in their study tried to find out whether there was a positive effect on student beliefs in solving the problem if given short duration intervention. The results of this study further explore the approaches that are considered effective to give a positive impact on the beliefs in solving the problem, rather than describe how the participants beliefs. Lerch (2004) also conducted a study on beliefs system. His research aims to see how making decisions play an important role in solving routine and nonroutine problems. The results of his study show that a beliefs system gives the people confidence to be able in solving the given problem.

Ozturk \& Guven (2015) conducted a case study of some high school students in Turkey aiming to check their beliefs in the process of solving the problem. This study uses interviews and observations. The results show that beliefs owned by students influence them in making decisions. In this study, Ozturk \& Guven recommends to conduct the same case studies on samples with different country backgrounds as they consider the beliefs of a system owned by a person to be influenced by a country or cultural background. This current study goes from the opportunities and suggestions that arise from studies that have been done before. This study aims to examine and explore in detail and in-depth related beliefs system owned by some students with a certain age range. To achieve this objective, in addition to collecting various related literatures, data collection was also done by providing two test questions as well as interviewing volunteer-selected participants.

Until now, according to experts there is no exact definition related beliefs system. Schoenfeld (1985) still analogize beliefs system as a mathematical point of view owned by someone. Beliefs system can be distinguished by its object (Mc Leod, 1992); beliefs about mathematics, beliefs about self, beliefs about mathematics teaching, and beliefs about social context. Beliefs about mathematics tell about a person's point of view on the urgency of mathematics in life. Beliefs about self tell about a person's perspective on himself and his own ability to solve problems. Beliefs about mathematics teaching tell about one's point of view of existing mathematics teaching. While beliefs about social context tell about cultural issues that exist in mathematics education.

Belief about self is the chosen concern in this current study. It is chosen by researcher based on certain considerations. In solving a problem, in addition to a variety of thinking skills, a person is also required to have confidence in himself and his own ability. This belief and point of view are closely related to beliefs about self. Therefore, the researcher conducts case study research on some college students with a certain age range to know how beliefs about self they have in solving mathematical problems.

\section{Method}

For the purpose of this study, qualitative approach was applied. A case study method was employed to investigate the beliefs about self of college students in solving real worldmathematical problems according to their answers test and explanation obtained by clinical interview. The purpose of this case study was to describe the current situation in detail rather than draw the generalization. Mathematical and clinical interview were conducted separately for each participant. The participants for this study are four college students who are 18-22 years old. The selection of participants was based on voluntariness. 


\section{Results \& Discussion}

In this section, we will discuss the beliefs about self in solving mathematical problems of each participant separately. Each of four participants was given the different code. M1 is for participant 1, M2 is for participant 2, M3 is for participant 3, and M4 is for participant 4. These mathematical problems were distributed to them and the clinical interview also took place.

1. The circumstance of a rectangle field is 90 meters. If the length of its field equals to twice of its width, can you determine its length? Why?

2. Anita, Anida, and Annisa go to the fruit shop. Anita bought $1 \mathrm{~kg}$ of apples and $2 \mathrm{~kg}$ of oranges for Rp43.000,00. While Anida bought $2 \mathrm{~kg}$ of apples and $1 \mathrm{~kg}$ of oranges for Rp41.000,00. Annisa has only Rp50.000,00. If Annisa wants to buy $2 \mathrm{~kg}$ of apples and $2 \mathrm{~kg}$ of oranges, is it her money enough to pay?

\section{M1 Beliefs about Self in Solving Mathematical Problems}

M1 was given the first problem. She was asked to read the problem carefully. The researcher then asked M1 whether she had ever encountered the similar problems before. M1 confidently answered yes and even experienced to solve them. Researcher asked the M1 opinion about how to solve the given problem. M1 thought that the problem was pretty easy because she only needs to find the length of the field by determining its width first. M1 said that she can solve it because once completed the similar problems. However, not long after trying to solve the problem, M1 said that she was give up and felt her answer was weird. M1 then was given the second problem. The questions asked by researchers in interview session were similar to previous interview. In solving the second problem, M1 seems more confident than before because she found the solution and though that it was correct. M1 was asked about her beliefs on the solution. M1 then felt doubt because the price of $1 \mathrm{~kg}$ of orange that she found was considered as less logical. However, M1 surrendered and said that she did not want to recheck or revise her answer.

The explanation given by $\mathrm{M} 1$ in the interview can show the beliefs about self that she has in solving the mathematical problem. M1 believes that she does not have good skills in mathematics although she often encounters the similar problems before. This causes M1 to feel insecure in solving the given mathematical problem. M1 had tried to solve these problems even if the answer was not completed or not correct. However, despite realizing that the answer was probably not true, M1 chose to give up because she did not want to repeat the process of solving the mathematical problem. M1 assumes that no matter how many efforts that she makes in solving mathematical problem, she believes that her answers will most likely be false. This is due to M1's belief in her inability to solve the mathematical problem, even though she realizes that she should not think like that.

\section{M2 Beliefs about Self in Solving Mathematical Problems}

M2 was given the first problem. She was asked to read the problem carefully. The researcher then asked M2 whether she had previously encountered a similar problem. M2 replied that she had experienced the similar problem before. The researcher then asked M2's opinion about the given problem and the way she would do to solve the problem. M2 replied he would try to solve the problem because she had experience with similar problems. M2 could determine the asked length. However, M2 did not give the complete answer. She did not relate the answer to the asked question and felt enough just by doing a mathematical calculation. The researcher then asked if M2 felt confident with her answer. M2 said that she 
was pretty sure. Then M2 was given the second problem. The questions asked by the researcher were similar to those asked in the previous interview. For the second problem, M2 said that she was pretty sure that she could solve it because she felt familiar with this kind of problems. After completing the second problem, M2 was asked about her belief about answer. M2 felt confident because the solution was obtained through appropriate procedure. M2 also said that she had considerable experiences in solving similar problems. The explanation given by $\mathrm{M} 2$ in the interview can show the beliefs about self that she has in solving the mathematical problem. M2 is less convinced that she has good skills in mathematics even though she could solve both given problems correctly. She will become more confident in her abilities if only she felt that she has experiences in solving the similar problems.

\section{M3 Beliefs about Self in Solving Mathematical Problems}

M3 was given the first problem. She was asked to read the problem carefully. The researcher then asked M3 whether she had previously encountered a similar problem. M3 replied confidently that she had experienced similar problems before. The researcher then asked M3's opinion on the given problem and the way she would do to solve it. M3 replied that she could solve it by finding the width of the field first. Then, M3 could found the length of the field. In addition, M3 also related her calculation with the asked question. The researcher then asked whether she was convinced with her answer. M3 replied that she was very confident because she had experienced in solving similar problems before.

After that, M3 is given the second problem. The questions asked by the researcher are similar to those asked in the previous interview. For the second problem, M4 said that she also believed that she could solve it because she has experienced in solving similar problems before. After solving the second problem, M3 was asked about her belief on her answer. M3 did convince because the solving process was appropriate to the procedure. M3 also said that she has many experiences in solving similar problems. The explanation given by M3 in the interview can show the beliefs about self that she has in solving the mathematical problem. M3 believes very well that she has a good ability in mathematics. M3 confidence is reasonable. It is because she has experiences in solving similar problems.

\section{M4 Beliefs about Self in Solving Mathematical Problems}

M4 was given the first problem. She was asked to read the problem carefully. The researcher then asked M4 whether she had previously encountered a similar problem. M4 admitted that she had never studied this kind of topic before. The researcher then asked whether M4 could solve the given problem. M4 answered she could not because she convinced that she would not understand the problem. After being motivated, M4 still did not want to solve the problem and chose to give up. M4 chose to leave the answer sheet for problem 1 blank. Then M4 was given the second problem. The questions asked by the researcher were similar to those asked in the previous interview. For the second problem, M4 responded with much more confidence than before because she admitted that this kind of problem had been met before. M4 was pleased that she had found the answer and felt better than encountering the problem 1. M4 was asked about her belief in the answers. M4 was pretty sure because she had used the mathematical procedure that she considered appropriate. The explanation given by M4 in the interview can show the beliefs about self that she has in solving the mathematical problem. M4 believes that she does not always have good skills in mathematics. This causes M4 to feel less confident in solving the given mathematical problem. M4 tend to choose giving up from the beginning and do not want to try at all. M4 thinks that it would be better to give up earlier than to face difficulty in solving problems then. 
In this case study, it is revealed that each of observed participants has beliefs about self. However, the beliefs about self that they have can be positive or negative orientation. Participant who has better positive beliefs about self are M3. In solving both mathematical problems given, she always felt confident to find a solution. M2 also has the positive beliefs about self, but it is not as well as M3. M2 sometimes still has doubts about herself, but the doubt will quickly disappear when she gets support. M1 has the positive beliefs about self that is lower than M3 and M2. M1 almost wanted to give up in solving the given problems, but she kept trying even though the answer that she found was incorrect. Based on this study, researcher thought that the positive beliefs about self is very influenced by experience factor. Experience in solving problems will encourage someone to be more confident in solving the other new problems. Not only positive beliefs about self, but also there were participant who has negative beliefs about self. M4 was assumed to have negative beliefs about self because in encountering the first problem, she strongly believed that she would not be able at all. Not only was she unable, she also assumed that she would not even be able to understand the problems given to her. It was because for M4, trying to understand the problem was something heavy and will waste energy. Therefore, M4 chose to surrender from the beginning rather than have to find difficulties in solving the problem then.

\section{Conclusion}

Problem solving is a scientific process through by a person, starting from understanding the problem to determine the needed information in finding solution to evaluating the appropriateness of the solution with the asked question (Williams, 2003). Problem solving process is influenced by certain factors. Schoenfeld (1992) divides the factors that affect the problem-solving process into four. First, resources that include formal and informal knowledge related facts and routines. Secondly, heuristic that refers to the used strategy and techniques. The third, control including method used by a person to examine the problem-solving process. Fourth, the beliefs system that is a person's mathematical perception about himself, his environment, or the encountered topic.

Beliefs system can be classified by its object (Mc Leod, 1992) including beliefs about mathematics, beliefs about self, beliefs about mathematics teaching, and beliefs about social context. Beliefs about self tell about a person's perspective on himself and his own ability to solve problems. While we are talking beliefs about self, it means we are talking about confidence, self-concept, or other similar attributes (Mc Leod, 1992). Some scholars define confidence in diverse expressions, but they all share the same characteristic, that is one's belief and feelings on his own abilities (Hendriana, Rohaeti, \& Sumarmo, 2017). This kind of beliefs will encourage someone to be able in giving the best effort in solving the encountered mathematical problems.

When a person believes that he has the ability to solve mathematical problems, then he will decide to solve them. He will keep trying to solve the problem although it is possible that he will not find the solution. Otherwise, when a person believes that he does not have the ability to solve mathematical problems, then he will decide not to solve them. This research is a case study concerning the beliefs about self in which the result cannot be generalized. But at least, we can know that beliefs about self play an important role in decision making or behavior of someone. Beliefs about self owned by someone can give a positive or negative effect to him. It is strongly recommended to conduct a similar study with larger sample. 


\section{Acknowledgement}

I would like to thank the Indonesia Endowment Fund for Education of Indonesian Republic (LPDP RI) for supporting this research.

\section{References}

Bayaga, A., Wadesango, N., \& Wadesango, O. V. (2015). Impact of teachers' beliefs on mathematics education. Africa Education Review, 12(2), 280-293. https://doi.org/10.1080/18146627.2015.1108008

Brown, T. (2016). Rationality and belief in learning mathematics, (December 2015), 75-90. https://doi.org/10.1007/s10649-015-9670-7

Charles, R. T., \& Lester, F. (1982). Teaching problem solving; what, why \& how. Palo Alto, CA: Dale Seymour

Creswell, J.W. (2013). Research Design: Qualitative, Quantitative, and Mixed Methods Approaches $2^{\text {nd }}$ edition. California: Sage Publications, Inc.

Diemer, M. A., Marchand, A. D., \& Mckellar, S. E. (2016). Promotive and Corrosive Factors in African American Students ' Math Beliefs and Achievement. Journal of Youth and Adolescence, 45(6), 1208-1225. https://doi.org/10.1007/s10964-016-0439-9

Gomez-Chacon, I. M. (2000). Affective influences in the knowledge of mathematics. Educational Studies in Mathematics, 43, 149-168

Grootenboer, P., \& Marshman, M. (2016). Mathematics, Affect and Learning, 13-34. https://doi.org/10.1007/978-981-287-679-9

Hendriana, H., Rohaeti, E.E., \& Sumarmo, U. (2017) Hard Skills dan Soft Skills Matematik Siswa. Bandung: Refika Aditama

Hofer, B., \& Pintrich, P. (1997). The development of epistemological theories: beliefs about knowledge and knowing and their relationship to learning. Review of Educational Research, 67(1), 88-140

Ignacio, N. G., Nieto, L. J. B., \& Barona, E. G. (2006). The Affective Domain in Mathematics Learning. International Electronic Journal of Mathematics Education, 1(1), 16-32

Je, A. (1999). G oals, Values, and Beliefs as Predictors of Achievement and Effort in High School Mathem atics Classes 1

Kloosterman, P., \& Stage, F. (1992). Measuring beliefs about mathematical problem solving. School Science and Mathematics, 92(3), 109-115

Lerch, C. M. (2004). Control decisions and personal beliefs: Their effect on solving mathematical problems. Journal of Mathematical Behavior, 23, 21-36

Leder, G. C. (2008). Beliefs: What lies behind the mirror. In B. Sriraman (Ed.), Beliefs and mathematics (pp. 39-54). Charlotte, NC: Information Age Publishing

Martinot, D., \& Désert, M. (2007). Awareness of a gender stereotype, personal beliefs and self-perceptions regarding math ability : when boys do not surpass girls, 455-471. https://doi.org/10.1007/s11218-007-9028-9

Mcleod, D. B., \& Mcleod, S. H. (2002). Chapter 7 Synthesis - Beliefs And Mathematics Education : Implications For Learning, Teaching, And Research

Mtetwa, D., \& Garofalo, J. (n.d.). Beliefs About Mathematics : A N Overlooked Aspect Of Student Difficulties, (May 1989)

Op, P., Corte, E. De, \& Verschaffel, L. (2006). Epistemic dimensions of students ' mathematics-related belief systems, 45, 57-70. https://doi.org/10.1016/j.ijer.2006.08.004 
Ozturk, T., \& Guven, B. (2016). Evaluating Students 'Beliefs in Problem Solving Process : A Case Study. Eurasia Journal of Mathematics, Science \& Technology Education, 12(2), 411-429. https://doi.org/10.12973/eurasia.2016.1208a

Radford, L. (2015). From beliefs to dynamic affect systems in mathematics education. https://doi.org/10.1007/978-3-319-06808-4

Schoenfeld, A. H. (1985). Mathematical problem solving. Orlando, FL: Academic Press

Schoenfeld, A. H. (1992). Learning to think mathematically: Problem solving, metacognition, and sense making in mathematics. In D. A. Grouws (Ed.), Handbook of research on mathematics teaching (pp. 334-370). New York: MacMillan Publishing

Schorr, R. Y., \& Warner, L. B. (2011). Beliefs and engagement structures : behind the affective dimension of mathematical learning, 547-560. https://doi.org/10.1007/s11858-011$0348-Z$

Stylianides, A. J., \& Stylianides, G. J. (2014). Impacting positively on students' mathematical problemsolving beliefs: An instructional intervention of short duration. The Journal of Mathematical Behavior, 23, 8-29

Suherman, Erman. (2003). Strategi Pembelajaran Matematika Kontemporer (Common TextBook). rev.ed. Bandung: UPI

Viholainen, A., Asikainen, M., \& Hirvonen, P. E. (2014). Mathematics student teachers' epistemological beliefs about the nature of mathematics and the goals of mathematics teaching and learning in the beginning of their studies. Eurasia Journal of Mathematics, Science \& Technology Education, 10(2), 159-171. doi: 10.12973/eurasia.2014.1028a 